\title{
Anticonvulsant use and bone health in a population-based study of men and women: cross-sectional data from the Geelong Osteoporosis Study
}

Vinoomika Chandrasekaran ${ }^{1 *}$ (D), Julie A. Pasco ${ }^{1,2,3,4}$, Amanda L. Stuart ${ }^{1}$, Sharon L. Brennan-Olsen ${ }^{3,5,6,7}$, Michael Berk ${ }^{1,2,4,8,9,10}$, Jason M. Hodge ${ }^{1,2,11}$, Rasika M. Samarasinghe ${ }^{1}$ and Lana J. Williams ${ }^{1}$

\begin{abstract}
Background: Anticonvulsant use has been linked to bone deficits in specific patient populations. We studied the association between anticonvulsant use and bone health in a population-based sample of men and women.

Methods: Data from 926 men (24-73 yr) and 1070 women (21-94 yr) participating in the Geelong Osteoporosis Study were included. Bone mineral density $\left(B M D, g / \mathrm{cm}^{2}\right)$ of the PA-spine and total hip was measured using dualenergy X-ray absorptiometry (Lunar). Bone quality was determined using quantitative heel ultrasound (QUS). Anthropometry was conducted and socioeconomic status was determined. Medication and lifestyle information was obtained via questionnaire. Linear regression was used to test associations between anticonvulsant use and bone health before and after adjustment for potential confounders.

Results: Seventeen (1.8\%) men and 20 (1.9\%) women reported anticonvulsant use. In men, anticonvulsant users had 9.1\% lower adjusted mean BMD at the spine and hip compared to non-users. Body mass index was an effect modifier at the spine. Anticonvulsant users also had 1.8\% lower speed of sound (SOS), 10.6\% lower broadband ultrasound attenuation (BUA) and 13.7\% lower stiffness index (SI) compared to non-users. In women, BMD tended to be lower at the hip compared to non-users as with the bone quality measure, BUA. No significant associations were observed at the spine or the other bone quality measures, SOS and SI.
\end{abstract}

Conclusion: Our data suggest that bone quantity and quality, assessed using BMD and QUS, are lower for men and possibly women who use anticonvulsants. While further exploration into potential mechanisms is needed, our findings suggest that monitoring bone health among users of anticonvulsants is warranted.

Keywords: Bone mineral density, Quantitative heel ultrasound, Anticonvulsants, Osteoporosis, psychiatry, neuroscience, medical comorbidity

\footnotetext{
* Correspondence: vchand@deakin.edu.au

${ }^{1}$ IMPACT, The Institute for Mental and Physical Health and Clinical

Translation, School of Medicine, Deakin University, PO Box 281, Barwon

Health, Geelong, Vic 3220, Australia

Full list of author information is available at the end of the article
}

C The Author(s). 2021 Open Access This article is licensed under a Creative Commons Attribution 4.0 International License, which permits use, sharing, adaptation, distribution and reproduction in any medium or format, as long as you give appropriate credit to the original author(s) and the source, provide a link to the Creative Commons licence, and indicate if changes were made. The images or other third party material in this article are included in the article's Creative Commons licence, unless indicated otherwise in a credit line to the material. If material is not included in the article's Creative Commons licence and your intended use is not permitted by statutory regulation or exceeds the permitted use, you will need to obtain permission directly from the copyright holder. To view a copy of this licence, visit http://creativecommons.org/licenses/by/4.0/. The Creative Commons Public Domain Dedication waiver (http://creativecommons.org/publicdomain/zero/1.0/) applies to the data made available in this article, unless otherwise stated in a credit line to the data. 


\section{Background}

Osteoporosis is an osteodegenerative disease of multifactorial aetiology, often undiagnosed until a fracture occurs [1]. As a growing public health concern, osteoporosis also affects independence, quality of life and increases risk of mortality [2]. The lifetime risk of developing an osteoporotic fracture in industrialised nations is $40-56 \%$ for women and $20-30 \%$ for men above the age of 50 years [3]. Among those aged 50 years and over, the prevalence of osteoporosis or low bone mass is estimated to increase by 31\% between 2012 and 2022 [4].

Dual energy X-ray absorptiometry (DXA) measures bone mineral density (BMD), and is currently the key assessment tool for diagnosing osteoporosis [5]. However, being a 2-dimensional measure, BMD does not sufficiently explain variance in fracture outcomes amongst individuals with similar BMD measures [6], thus additional bone measures may be useful. Quantitative heel ultrasound (QUS) is a radiation-free, portable, noninvasive, inexpensive screening method to assess bone quality, measuring 3-dimensional parameters such as bone structure and elasticity to explain variance in bone strength [5, 7]. Trabecular bone in sites such as the vertebral body and the calcaneus is more susceptible to the effects of altered metabolism [8].

The risk factors for osteoporosis are multifactorial and include age, poor lifestyle, inadequate nutrition, smoking, substance abuse and certain medications and illnesses [1, 9]. Several medications, including anticonvulsants such as valproate, have been associated with increased fracture risk [10]. Anticonvulsants are a mainstay in the treatment of psychiatric and neurological illnesses and have been theorised to have agonistic effects on the glutamatergic and GABAergic neuronal pathways [11] and/or calcium, sodium and potassium voltage gated channels, thereby reversing their neuroexcitatory effects [12]. Other possible mechanisms associated with an anticonvulsant-related decline in bone health are impaired calcium absorption or decreased calcium availability due to calcitonin deficiency, altered sex hormones, liver enzyme induction, inhibition of response to parathyroid hormone or hyperparathyroidism [13, 14]. Further, any potential anticonvulsant-induced alterations in body composition may additionally influence fracture risk [15].

Anticonvulsants have been associated with increased fracture risk in adults $[10,16]$ and decreased BMD in children [17]. Few studies have investigated anticonvulsant use on QUS parameters [18, 19]. A preclinical analysis of levetiracetam use in rats decreased bone quality, but not BMD, suggesting that DXA measurements may not sufficiently detect all anticonvulsant-related bone deficits [20]. Large studies simultaneously assessing how anticonvulsant use affects bone quality and quantity, after considering potential confounding factors are also sparse. Thus, we aimed to assess the relationship between anticonvulsant use and bone quantity and quality in a large population-based sample of men and women.

\section{Methods \\ Participants}

This study utilised data from men and women participating in the Geelong Osteoporosis Study (GOS), a large, ongoing, population-based study conducted in the Barwon Statistical Division in south-eastern Australia [21]. Initially, 1494 women (aged 20-94 years, participation $77.1 \%$ ) and 1540 men (aged 20-93 years, participation $67 \%$ ) were randomly selected from the Commonwealth of Australia electoral rolls (where voting is compulsory), between 1994 and 1997, and 2001 and 2006, respectively. Participants have been invited for two to five yearly assessments. An additional sample of 246 women aged 20-29 years was recruited (participation 70.9\%) between 2004 and 2008, allowing for continuing investigation of the full adult age range.

For this cross-sectional analysis, data collected at the 10-year follow-up for women and 5-year follow-up for men was utilised. Of the 1127 women who participated in the 10-year follow-up, participants for whom bone data were not available were excluded, resulting in a final sample of 1070, aged 20-94 years. Of the 978 men who participated in their 5-year follow-up, similarly, participants for whom bone data were not available were excluded, resulting in a final sample of 926, aged 24-98 years.

\section{Measurement of the outcome variables}

BMD $\left(\mathrm{g} / \mathrm{cm}^{2}\right)$ was measured at the spine (PA projection, L2-4) and total hip for men (Lunar Prodigy, GE, Madison, WI, USA) and women (DPX-L, GE, Madison, WI) [21]. Trained technicians carried out all examinations and performed daily calibrations of the densitometers with an equipment-specific phantom.

At the same time as BMD was measured, bone quality was determined by calcaneus QUS (Achilles Insight Ultrasonometer, GE Lunar, Madison, WI, USA) of the left heel, yielding the following parameters: broadband ultrasound attenuation [BUA $(\mathrm{dB} / \mathrm{MHz})]$, reflecting microarchitecture and bone density, speed of sound [SOS $(\mathrm{m} / \mathrm{s})]$, reflecting elasticity and bone density and stiffness index [SI (\%)], a calculated clinical index [22]. SOS and BUA measure the speed and frequency-dependent ultrasound attenuation of ultrasound signals passing through soft tissue and trabecular bone [23]. SI is a combined parameter, calculated from these primary measures [24].

\section{Measurement of exposure variables}

The following data were collected concurrently with the bone health assessments: 


\section{Medication use}

Current medication use was determined via self-report. Participants were requested to bring a medication list or containers to their appointment to ensure accurate reporting. Exposure to anticonvulsants, and other medications known to affect bone, such as oral glucocorticoids, bisphosphonates, and thyroid medication were coded based on the Australian index of medications guidelines.

\section{Questionnaire data}

Information on daily alcohol use (g/day) and calcium intake (mg/day) was determined using a validated food frequency questionnaire [25]. Participants were classified as smokers if they reported current use at the time of assessment and habitual physical activity level was classified as active if vigorous or light exercise was performed regularly; otherwise participants were classified as sedentary.

\section{Other markers of bone health}

Osteoporosis status was identified as T-score $<-2.5$ at either the spine or total hip [26, 27]. Information regarding previous adult fracture was ascertained via radiological reports from medical imaging centres servicing the region. This method of fracture ascertainment has been previously validated [28].

\section{Anthropometric measures}

Body mass index (BMI) was calculated $\left(\mathrm{kg} / \mathrm{m}^{2}\right)$ from height, measured to the nearest $0.1 \mathrm{~cm}$, and body weight measured to the nearest $0.1 \mathrm{~kg}$.

\section{Socioeconomic status}

Area-based socio-economic status (SES) was established by matching the $\mathrm{x}-\mathrm{y}$ coordinates of participants' residential addresses to the Australian Bureau of Statistics' Index of Relative Socioeconomic Advantage and Disadvantage (IRSAD) data to determine a score for each participant. The IRSAD consists of information regarding income and skill level. IRSAD scores for this study were determined according to cut points of the Barwon Statistical Division and categorised into quintiles whereby SES quintile 1 was considered most disadvantaged and SES quintile 5 was most advantaged.

\section{Statistical analyses}

Minitab (Version 18; Minitab, State College Pa) was used to perform statistical analyses. Differences between anticonvulsant users and non-users were detected using ttests for continuous normally distributed variables, Kruskal-Wallis for non-parametric continuous variables and chi-square or Fisher's exact test for discrete variables. Multiple regression was used to explore associations between anticonvulsant use and a) BMD and b) QUS measures (BUA, SOS and SI). Data for men and women were analysed using separate statistical models. Confounders including age, BMI, smoking status, SES, physical activity and medications known to affect bone were tested sequentially and retained in the final model when significant $(p<0.05)$. Interactions between exposure variables were checked for effect modification in the final models.

\section{Results}

\section{Male sample}

Seventeen men $(1.8 \%)$ were anticonvulsant users at the time of assessment; phenytoin $(n=7)$, carbamazepine $(n=5)$, sodium valproate $(n=5)$, pregabalin $(n=1)$ and clonazepam $(n=1)$. Anticonvulsant users were older, less active, consumed less alcohol and were more likely to have a previous adult fracture than non-users; otherwise the groups were similar in regard to BMI, smoking status, calcium intake, osteoporosis status and SES (Table 1). Unadjusted BMD and QUS parameters are shown in Table 1.

BMI was an effect modifier in the relationship between anticonvulsant use and BMD at the spine, with the relationship differing for those above and below a BMI of $28.5 \mathrm{~kg} / \mathrm{m}^{2}$. For example, for users vs non-users, ageand BMI- adjusted mean BMD at the spine for men with a BMI of $25 \mathrm{~kg} / \mathrm{m}^{2}$ was 1.154 (95\% CI 1.039-1.269) vs $1.275(1.260-1.290) \mathrm{g} / \mathrm{cm}^{2}$, a BMI of $27 \mathrm{~kg} / \mathrm{m}^{2}$ was 1.231 (95\% CI 1.138-1.324) vs $1.291(1.278-1.304) \mathrm{g} / \mathrm{cm}^{2}$, a BMI of $29 \mathrm{~kg} / \mathrm{m}^{2}$ was 1.308 (95\% CI $1.204-1.412$ ) vs $1.307(1.293-1.321) \mathrm{g} / \mathrm{cm}^{2}$ and a BMI of $31 \mathrm{~kg} / \mathrm{m}^{2}$ was 1.385 (95\% CI 1.244-1.527) vs $1.323(1.306-1.340) \mathrm{g} /$ $\mathrm{cm}^{2}$ (all $p=0.033$ ). At the hip, age- and BMI- adjusted mean BMD was lower among anticonvulsant users compared to non-users [0.887 (95\% CI 0.830-0.944) vs 0.976 $\left.(0.968-0.984) \mathrm{g} / \mathrm{cm}^{2}, p=0.002\right]$. Smoking, physical activity, alcohol and calcium intake, SES and medications known to affect bone did not contribute to the final models.

After adjustment for age, BMI, smoking, alcohol and calcium intake, anticonvulsant use was associated with lower adjusted mean BUA [107.5 (95\% CI 99.4-115.7) vs $120.3(119.2-121.4) \mathrm{dB} / \mathrm{MHz}, \mathrm{p}=0.002]$, SOS [1543.1 (95\% CI 1521.8-1564.4) vs $1572.0(1569.1-1574.9) \mathrm{m} /$ sec, $p=0.008]$ and SI [86.2 (95\% CI 76.1-96.2) vs 99.9 (98.6-101.3) \%, p = 0.008] compared to non-use. Physical activity, SES and medications known to affect bone did not contribute to the final models.

\section{Female sample}

Twenty (1.9\%) women were anticonvulsant users at the time of assessment; carbamazepine $(n=6)$, sodium valproate $(n=4)$, clonazepam $(n=5)$, gabapentin $(n=3)$, 


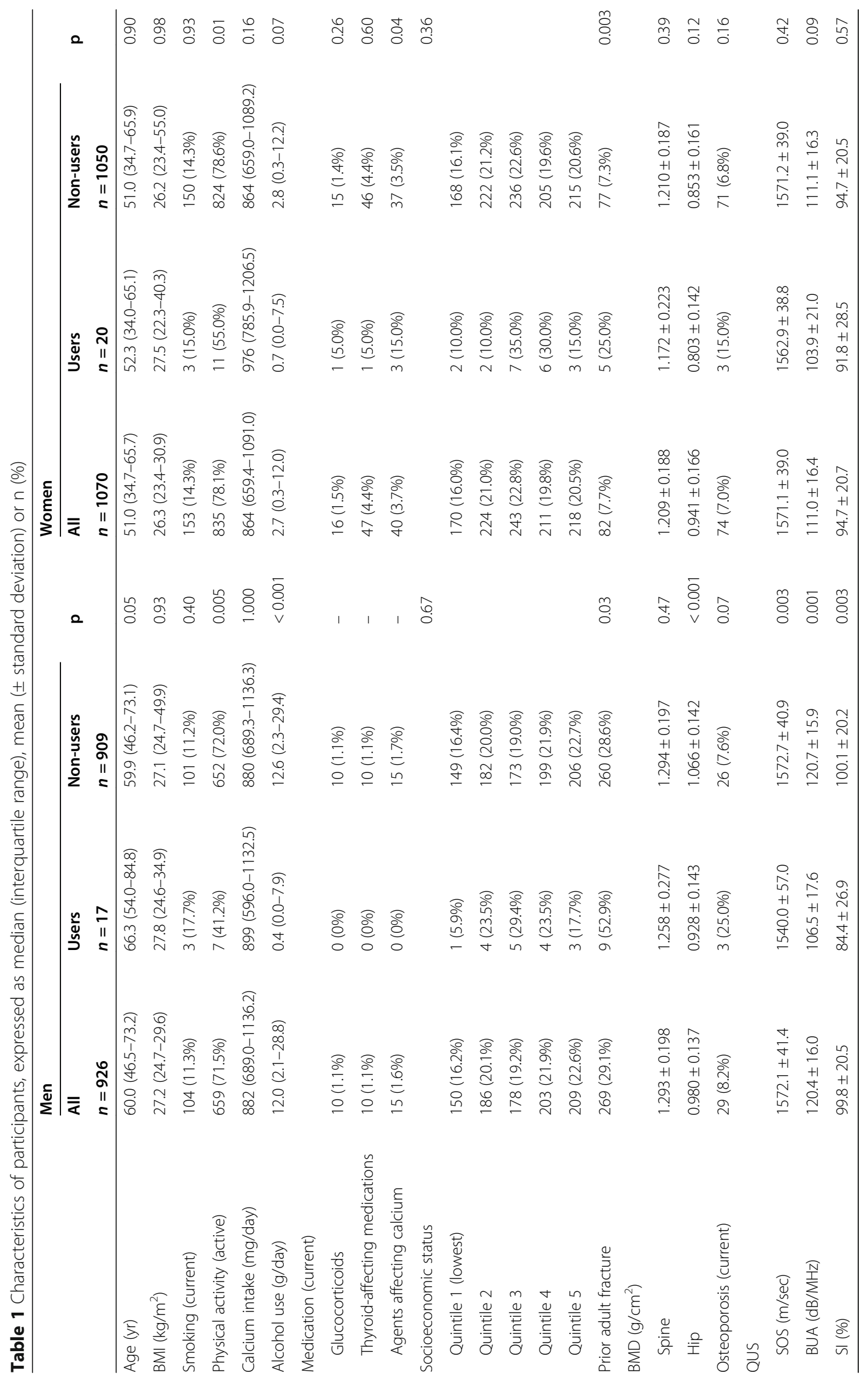


lamotrigine $(n=1)$ and pregabalin $(\mathrm{n}=1)$. Anticonvulsant users were less active, more likely to have a previous fracture and were more likely to take agents affecting calcium than non-users; otherwise the groups did not differ in regards to age, BMI, smoking status, calcium intake, alcohol use, SES, osteoporosis status or use of thyroid-affecting hormones and adrenal steroid hormones (Table 1). Unadjusted BMD and QUS parameters for users and non-users are shown in Table 1.

After adjustment for age and BMI, there were no differences detected in BMD at the spine between users and non-users of anticonvulsants [1.164 (95\% CI 1.090$1.239)$ vs $\left.1.200(1.190-1.211) \mathrm{g} / \mathrm{cm}^{2}, p=0.345\right]$, however, anticonvulsant users tended to have lower BMD at the hip compared to non-users [0.876 (0.821-0.931) vs 0.930 (0.922-0.938) units, $p=0.058]$.

After adjustment for age and BMI, anticonvulsant use was not associated with mean SOS [1565.0 (95\% CI $1547.8-1582.1)$ vs $1571.0(1568.7-1573.3) \mathrm{m} / \mathrm{sec}, p=$ 0.493] or SI [90.8 (95\% CI 82.8-98.9) vs 93.7 (92.6-94.8) $\%, p=0.484]$ but anticonvulsant users tended to have lower BUA than non-users [104.5 (95\% CI 97.8-111.3) vs $110.7(109.8-111.6) \mathrm{dB} / \mathrm{MHz}, p=0.075]$.

\section{Discussion}

This cross-sectional study investigated associations between anticonvulsant use and bone health in a large population-based sample of men and women. After adjustment for confounders, BMD and QUS parameters were generally lower in men using anticonvulsants compared to non-users. In women, this was not clearly the case, with the difference in BMD and QUS parameters between anticonvulsant users and non-users not reaching statistical significance.

Only two studies have looked at how anticonvulsant use affects QUS measures albeit in children and young adults. A small Italian study ( $n=164$, aged $2-21$ years) investigating how anticonvulsants affect DXA and QUS measures in girls with or without Rett Syndrome found that anticonvulsant therapy was associated with lower bone measures, although fracture risk was not elevated [18]. Similarly, a cross-sectional study conducted in Spain found that valproate, but not carbamazepine, phenobarbital, lamotrigine, topiramate, vigabatrine or phenytoin was associated with lower QUS measures in children ( $n=65$, aged $6.5 \pm 3.1$ years) compared to nonusers; despite having $27.3 \%$ of their treated group taking two or more anticonvulsants [19]. On the other hand, several studies have looked at associations between anticonvulsant use and BMD [29-32], although most studies have been conducted in patients with epilepsy and in paediatric populations [10]. It has been estimated that over $50 \%$ of anticonvulsant users develop bone anomalies [29], and studies conducted over time have shown that long-term use is associated with increased fracture risk and associated bone disease [30, 32]. In a large, multiethnic, postmenopausal cohort $(n=138,667$, aged 50 79 years), anticonvulsant use was associated with an increased fracture risk, which was further increased with polypharmacy and enzyme-inducing anticonvulsants rather than the non-enzyme inducing type [30]. Interestingly, anticonvulsant use was not associated with BMD at the spine, hip and total body, but was associated with falls risk. While our results reflect the association between anticonvulsants and bone health in adults, it appears that our findings are concordant with the existing literature, that while anticonvulsant use may be broadly associated with bone deficits, associations in girls and women are less clear.

Chronic anticonvulsant use has been associated with a 1.2-2.4-fold increase in fracture risk [33]; explained in part by hepatic enzyme-inducing anticonvulsants known to increase conversion of 25-hydroxyvitamin D into inactive metabolites [34]. Mezuk et al. [35] observed that although enzyme-inducing anticonvulsants may pose a greater fracture risk (HR 2.19, 95\% CI: 1.97-2.43), nonenzyme-inducing anticonvulsants are also associated with an increased fracture risk (HR 1.66, 95\% CI: 1.541.79). Additionally, Lee et al. [33] observed that first generation anticonvulsants such as valproic acid, carbamazepine, phenytoin and phenobarbital are associated with an increased rate of fragility fractures, when compared to newer agents.

Confounding by indication is another factor possibly playing a role. Anticonvulsants are used in the treatment of epilepsy and bipolar disorder, with both having been shown to be independently associated with increased fracture risk. In a recent systematic review, bipolar disorder was associated with a $20-80 \%$ increased risk of fracture, independent of age, sex, medication and comorbidities [9]. Decreased physical activity and other modifiable risk factors, such as diet, substance use, smoking, SES, sun exposure, medical comorbidities, polypharmacy and drug-induced metabolic imbalances may also contribute to the overall decline in bone health [36-38]. Falling, associated with seizures in epilepsy, has been proposed to be another mediating factor [39].

The results of this study, when taken in context of research showing that anticonvulsant use independently increases fracture risk, add to existing clinical findings, and may assist treatment decisions in managing an already vulnerable population. Adequate calcium supplementation could counteract the deleterious effects of anticonvulsants [40], while clinical trial evidence suggests that the association between calcium supplementation and improved bone health is weak [41]. The antiepileptic drug and osteoporosis prevention trial (ADOPT) reported similar findings, where over $69 \%$ of their cohort 
( $n=80$ men, aged $\geq 58$ years) had improved BMD measures with adequate calcium supplementation [42].

Both strengths and limitations need to be taken into consideration. Strengths of this study include the representative nature of the sample spanning the full adult age range, and the number of confounding variables tested. A limitation of this study is its cross-sectional nature, preventing conclusions on how BMD and QUS measures varied over time. Second, vitamin D status has not been considered. Other factors for consideration are a likely healthy participant bias and the small number of anticonvulsant users is an additional consideration, which also limited subgroup analyses of specific agents. Lastly, any unidentified confounding may affect our findings.

\section{Conclusion}

Both DXA and QUS measures in our study suggest an anticonvulsant-associated deficit in bone health, at least for men. Further exploration into mechanisms are warranted, as this information may inform clinical decisions and enable necessary preventative measures to be taken when prescribing anticonvulsants.

\section{Abbreviations \\ BMD: Bone mineral density; DXA: Dual-energy X-ray absorptiometry; QUS: Quantitative heel ultrasound; SOS: Speed of sound; BUA: Broadband ultrasound attenuation; SI: Stiffness index; GOS: Geelong Osteoporosis Study; IRSAD: Index of Relative Socioeconomic Advantage and Disadvantage; BMI: Body mass index; HR: Hazard ratio; Cl: Confidence interval; SES: Socioeconomic status; ADOPT: Antiepileptic drug and osteoporosis prevention trial}

\section{Acknowledgements}

Not applicable.

\author{
Authors' contributions \\ VC, ALS and LW designed the study and prepared the first draft of this \\ manuscript. ALS performed statistical analyses. All authors reviewed and \\ contributed to the intellectual content in this manuscript, approved the final \\ version and guarantee this work.
}

\section{Funding}

The study is supported by the National Health and Medical Research Council (NHMRC, of Australia) (GNT1104438). VC is supported by a Deakin University Postgraduate Research Scholarship, SLB-O is supported by a National Health and Medical Research Council (NHMRC) Career Development Fellowship (GNT1107510), MB is supported by a NHMRC Senior Principal Research Fellowship (1059660 and 1156072) and LJW is supported by a NHMRC Career Development Fellowship (1064272) and a NHMRC Emerging Research Fellowship (1174060)

\section{Availability of data and materials}

Participants' data available on request from Professor Julie Pasco, due to privacy/ethical restrictions.

\section{Ethics approval and consent to participate}

Ethics approval was obtained from the Human Research Ethics Committee at Barwon Health. All participants provided informed, written consent.

\section{Consent for publication}

Not applicable.

\section{Competing interests}

None of the authors has any relevant conflicts of interest related to the work under consideration for publication. JAP has received speaker fees from Amgen, Eli Lilly and Sanofi-Aventis and funding from the Geelong Region Medical Research Foundation, Barwon Health, Perpetual Trustees, The University of Melbourne, Deakin University, ANZ Charitable Trust, the American Society for Bone and Mineral Research, Amgen (Europe), GmBH, the BUPA Foundation, Osteoporosis Australia, Australia and New Zealand Bone and Mineral Society and the NHMRC. SLB-O has received Honorarium fees from Amgen Australia and Pfizer Australia, and Grant/Research support from the University of Melbourne, Deakin University, Arthritis Victoria, Arthritis Australia, Australian Association of Gerontology, and the City of Greater Geelong. MB has received Grant/Research Support from the NIH, Cooperative Research Centre, Simons Autism Foundation, Cancer Council of Victoria, Stanley Medical Research Foundation, Medical Benefits Fund, National Health and Medical Research Council, Medical Research Futures Fund, Beyond Blue, Rotary Health, A2 milk company, Meat and Livestock Board, Woolworths, Avant and the Harry Windsor Foundation, has been a speaker for Astra Zeneca, Lundbeck, Merck, Pfizer, and served as a consultant to Allergan, Astra Zeneca, Bioadvantex, Bionomics, Collaborative Medicinal Development, Lundbeck Merck, Pfizer and Servier. LJW has received Grant/Research support from Eli Lilly, Pfizer, The University of Melbourne, Deakin University and the NHMRC. VC, ALS, JH and RS have no conflict of interest.

\section{Author details}

${ }^{1}$ IMPACT, The Institute for Mental and Physical Health and Clinical Translation, School of Medicine, Deakin University, PO Box 281, Barwon Health, Geelong, Vic 3220, Australia. Barwon Health, University Hospital, Geelong, Australia. ${ }^{3}$ Department of Medicine-Western Health, The University of Melbourne, St Albans, Australia. ${ }^{4}$ Department of Epidemiology and Preventive Medicine, Monash University, Prahran, Australia. ${ }^{5}$ Australian Institute for Musculoskeletal Science (AIMSS), The University of Melbourne and Western Health, St Albans, Australia. ${ }^{6}$ Deakin University, School of Health and Social Development, Geelong, Waterfront, Australia. ${ }^{7}$ Institute for Health Transformation, Deakin University, Burwood, Australia. ${ }^{8}$ Department of Psychiatry, University of Melbourne, Parkville, Australia. ${ }^{9}$ Florey Institute of Neuroscience and Mental Health, Parkville, Australia. ${ }^{10}$ Orygen the National Centre of Excellence in Youth Mental Health, Parkville, Australia. ${ }^{11}$ Geelong Centre for Emerging Infectious Diseases, Geelong, Australia.

Received: 23 July 2020 Accepted: 3 February 2021

Published online: 11 February 2021

\section{References}

1. Schürer C, Wallaschofski H, Nauck M, Völzke H, Schober H-C, Hannemann A. Fracture risk and risk factors for osteoporosis. Dtsch Arztebl Int. 2015; 112(21-22):365-71.

2. Pasco JA, Holloway-Kew KL, Hyde NK, Tembo MC, Rufus PG, Sui SX, Berk M, Kotowicz MA. Pretiree lifestyles in relation to musculoskeletal health: crosssectional data from the Geelong Osteoporosis Study. JCSM Clinical Reports. 2018;3:1-12.

3. Sozen T, Ozisik L, Basaran NC. An overview and management of osteoporosis. Eur J Rheumatol. 2017;4(1):46-56.

4. Watts J, Abimanyi-Ochom J, Sanders K. Osteoporosis costing all Australians A new burden of disease analysis - 2012 to 2022. Glebe, NSW: Osteoporosis Australia; 2012.

5. Knapp KM. Quantitative ultrasound and bone health. Salud Publica Mex 2009;51(Suppl 1):S18-24.

6. Lewiecki EM, Binkley N, Morgan SL, Shuhart CR, Camargos BM, Carey JJ, Gordon CM, Jankowski LG, Lee JK, Leslie WD. Best practices for dual-energy $X$-ray absorptiometry measurement and reporting: International Society for Clinical Densitometry Guidance. J Clin Densitom. 2016;19(2):127-40.

7. Oo WM, Naganathan V, Bo MT, Hunter DJ. Clinical utilities of quantitative ultrasound in osteoporosis associated with inflammatory rheumatic diseases. Quant Imaging Med Surg. 2018;8(1):100-13.

8. Rouillard S, Lane NE. Hepatic osteodystrophy. Hepatology. 2001;33(1):301-7.

9. Chandrasekaran V, Brennan-Olsen SL, Stuart AL, Pasco JA, Berk M, Hodge JM, Williams LJ. Bipolar disorder and bone health: a systematic review. J Affect Disord. 2019;249:262-9.

10. Dussault PM, Lazzari AA. Epilepsy and osteoporosis risk. Curr Opin Endocrinol Diabetes Obesity. 2017;24(6):395-401. 
11. Johannessen Landmark C. Antiepileptic drugs in non-epilepsy disorders: relations between mechanisms of action and clinical efficacy. CNS drugs. 2008;22(1):27-47.

12. Grunze H, Schlösser S, Amann B, Walden J. Anticonvulsant drugs in bipolar disorder. Dialogues Clin Neurosci. 1999;1(1):24-40.

13. Pack AM. The association between antiepileptic drugs and bone disease. Epilepsy Curr. 2003;3(3):91-5.

14. Stoffel-Wagner B, Bauer J, Flügel D, Brennemann W, Klingmüller D, Elger CE. Serum sex hormones are altered in patients with chronic temporal lobe epilepsy receiving anticonvulsant medication. Epilepsia. 1998;39(11):1164-73.

15. Hars M, Trombetti A. Body composition assessment in the prediction of osteoporotic fractures. Curr Opin Rheumatol. 2017;29(4):394-401.

16. Shen C, Chen F, Zhang Y, Guo Y, Ding M. Association between use of antiepileptic drugs and fracture risk: a systematic review and meta-analysis. Bone. 2014;64:246-53.

17. Zhang Y, Zheng Y-x, Zhu J-m, Zhang J-m, Zheng Z. Effects of antiepileptic drugs on bone mineral density and bone metabolism in children: a metaanalysis. J Zhejiang Univ Sci B. 2015;16(7):611-21.

18. Cepollaro C, Gonnelli S, Bruni D, Pacini S, Martini S, Franci MB, Gennari L, Rossi S, Hayek G, Zappella M, et al. Dual X-ray absorptiometry and bone ultrasonography in patients with Rett syndrome. Calcif Tissue Int. 2001;69(5): 259-62.

19. Vera V, Moran JM, Barros P, Canal-Macias ML, Guerrero-Bonmatty R, CostaFernandez C, Lavado-Garcia JM, Roncero-Martin R, Pedrera-Zamorano JD. Greater calcium intake is associated with better bone health measured by quantitative ultrasound of the phalanges in pediatric patients treated with anticonvulsant drugs. Nutrients. 2015;7(12):9908-17.

20. Nissen-Meyer LS, Svalheim S, Tauboll E, Reppe S, Lekva T, Solberg LB, Melhus G, Reinholt FP, Gjerstad L, Jemtland R. Levetiracetam, phenytoin, and valproate act differently on rat bone mass, structure, and metabolism. Epilepsia. 2007;48(10):1850-60.

21. Pasco JA, Nicholson GC, Kotowicz MA. Cohort profile: Geelong osteoporosis study. Int J Epidemiol. 2012;41(6):1565-75.

22. Economos CD, Sacheck JM, Wacker W, Shea K, Naumova EN. Precision of lunar Achilles+ bone quality measurements: time dependency and multiple machine use in field studies. Br J Radiol. 2007;80(959):919-25.

23. Gluer CC, Wu CY, Jergas M, Goldstein SA, Genant HK. Three quantitative ultrasound parameters reflect bone structure. Calcif Tissue Int. 1994: 55(1):46-52.

24. Chin K, Ima-Nirwana S. Calcaneal quantitative ultrasound as a determinant of bone health status: what properties of bone does it reflect? Int J Med Sci. 2013;10(12):1778-83.

25. Wheeler C, Rutishauser I, Conn J, O'Dea K. Reproducibility of a meal-based food frequency questionnaire. The influence of format and time interval between questionnaires. Eur J Clin Nutr. 1994;48(11):795-809.

26. Henry MJ, Pasco JA, Korn S, Gibson JE, Kotowicz MA, Nicholson GC. Bone mineral density reference ranges for Australian men: Geelong osteoporosis study. Osteoporos Int. 2010;21(6):909-17.

27. Henry MJ, Pasco JA, Pocock NA, Nicholson GC, Kotowicz MA. Reference ranges for bone densitometers adopted Australia-wide: Geelong osteoporosis study. Australas Radiol. 2004;48(4):473-5.

28. Pasco JA, Henry MJ, Gaudry TM, Nicholson GC, Kotowicz MA. Identification of incident fractures: the Geelong osteoporosis study. Aust NZ J Med. 1999; 29(2):203-6.

29. Fan HC, Lee HS, Chang KP, Lee YY, Lai HC, Hung PL, Lee HF, Chi CS. The Impact of Anti-Epileptic Drugs on Growth and Bone Metabolism. Int J Mol Sci. 2016;17(8):1242.

30. Carbone LD, Johnson KC, Robbins J, Larson JC, Curb JD, Watson K, Gass M, Lacroix AZ. Antiepileptic drug use, falls, fractures, and BMD in

postmenopausal women: findings from the women's health initiative (WHI). J Bone Miner Res. 2010;25(4):873-81.

31. Pack AM, Olarte LS, Morrell MJ, Flaster E, Resor SR, Shane E. Bone mineral density in an outpatient population receiving enzyme-inducing antiepileptic drugs. Epilepsy Behav. 2003;4(2):169-74.

32. Souverein PC, Webb DJ, Petri H, Weil J, Van Staa TP, Egberts T. Incidence of fractures among epilepsy patients: a population-based retrospective cohort study in the general practice research database. Epilepsia. 2005;46(2):304-10.

33. Lee RH, Lyles KW, Colón-Emeric C. A review of the effect of anticonvulsant medications on bone mineral density and fracture risk. Am J Geriatr Pharmacother. 2010:8(1):34-46

34. Hahn TJ. Bone complications of anticonvulsants. Drugs. 1976;12(3):201-11.
35. Mezuk B, Morden NE, Ganoczy D, Post EP, Kilbourne AM. Anticonvulsant use, bipolar disorder, and risk of fracture among older adults in the veterans health administration. Am J Geriatr Psychiatry. 2010;18(3):245-55.

36. Weaver CM, Gordon CM, Janz KF, Kalkwarf HJ, Lappe JM, Lewis R, O'Karma M, Wallace TC, Zemel BS. The National Osteoporosis Foundation's position statement on peak bone mass development and lifestyle factors: a systematic review and implementation recommendations. Osteoporos Int. 2016;27(4):1281-386

37. Sheth RD. Metabolic concerns associated with antiepileptic medications. Neurology. 2004;63(10 Suppl 4):S24-9.

38. Hartikainen S, Lonnroos $\mathrm{E}$, Louhivuori K. Medication as a risk factor for falls: critical systematic review. J Gerontol A Biol Sci Med Sci. 2007; 62(10):1172-81.

39. Pack AM, Morrell MJ. Epilepsy and bone health in adults. Epilepsy Behav. 2004:5(Suppl 2):S24-9.

40. Fernandez $H$, Mohammed HT, Patel T. Vitamin D supplementation for bone health in adults with epilepsy: a systematic review. Epilepsia. 2018;59(4):885-96.

41. Bolland MJ, Grey A, Avenell A. Effects of vitamin D supplementation on musculoskeletal health: a systematic review, meta-analysis, and trial sequential analysis. Lancet Diabetes Endocrinol. 2018;6(11):847-58.

42. Lazzari AA, Dussault PM, Thakore-James M, Gagnon D, Baker E, Davis SA, Houranieh AM. Prevention of bone loss and vertebral fractures in patients with chronic epilepsy - antiepileptic drug and osteoporosis prevention trial. Epilepsia. 2013;54(11):1997-2004.

\section{Publisher's Note}

Springer Nature remains neutral with regard to jurisdictional claims in published maps and institutional affiliations.
Ready to submit your research? Choose BMC and benefit from:

- fast, convenient online submission

- thorough peer review by experienced researchers in your field

- rapid publication on acceptance

- support for research data, including large and complex data types

- gold Open Access which fosters wider collaboration and increased citations

- maximum visibility for your research: over $100 \mathrm{M}$ website views per year

At $\mathrm{BMC}$, research is always in progress.

Learn more biomedcentral.com/submissions 